\title{
Um Macau "Imaginado" em Língua Portuguesa
}

\author{
Cristina Água-Mel (UIBE) ${ }^{1}$
}

Resumo: Apesar da decisão de manter o Português como segunda língua oficial da Região Administrativa Especial de Macau (RAEM), pouca ou nenhuma atenção é prestada à definição de uma política de língua ou à reforma educativa necessária ao processo de implementação de um verdadeiro bilinguismo ou, preferencialmente, trilinguismo que, tal como aconteceu em países e regiões vizinhas, contribua para o desenvolvimento económico e social de Macau. Esse desinvestimento político, aliado à falta de um sentimento de pertença à terra ou coesão comunitária entre a população que reside no território, impediu um processo de construção identitária no qual o Português e a sua herança histórico-cultural funcionem como mais-valias do desenvolvimento e afirmação da RAEM, não apenas na região onde se situa geograficamente, mas no mundo.

Palavras-chave: identidade; língua; políticas linguísticas.

O contacto entre populações com diferentes línguas maternas obriga ao desenvolvimento de recursos linguísticos que vão desde a formação de pidgins e crioulos até situações de paridade linguística ou bilinguismo. As diferentes condições e circunstâncias em que a interação socioeconómica se processa entre falantes dá origem a vários tipos de bilinguismo. $\mathrm{O}$ "bilinguismo natural" decorre da exposição de uma criança a duas ou mais línguas no seio de um ambiente familiar ou escolar. A movimentação de pessoas entre países ou regiões gera um "bilinguismo voluntário" adotado sempre que, por razões políticas ou socioeconómicas, os falantes se veem obrigados a "funcionar" linguisticamente numa língua (ou línguas) nãomaterna(s). Porque a língua é indissociável do processo de construção identitária nacional, são frequentemente tomadas decisões políticas que criam situações de "bilinguismo impessoal", no qual a língua é adotada exclusivamente por razões políticas e, raramente, ou até mesmo nunca, usada pela população residente desse espaço. Existe também um tipo de "bilinguismo decretado" que resulta da imposição legislativa que obriga ao uso da língua em determinados contextos como, por exemplo, dentro da estrutura da administração pública de um país ou região.

A Região Administrativa Especial de Macau (daqui por diante referida como RAEM) reúne, no seu minúsculo espaço, todos os exemplos de bilinguismo atrás mencionados e apresenta inclusivamente características

1 Docente do Departamento de Português da Universidade de Economia e Negócios Internacionais de Pequim, China. Email: aguamelc@gmail.com 
linguísticas peculiares como as identificadas pelo sociolinguista Andrew Moody. Segundo este investigador, que desde 2003 trabalha no Departamento de Inglês da Universidade de Macau, fora das estruturas administrativas do governo do território, a língua portuguesa apresenta um estatuto de jure enquanto que a língua inglesa desfruta de um estatuto de facto (2008, p. 4). Por outras palavras, o Português é imposto por decreto mas o seu uso não se generalizou entre a população e a sua aprendizagem só é empreendida pelos residentes que desejam trabalhar na função pública. Moody acrescenta que a adoção do Português como língua oficial permitiu, por um lado, manter os postos de trabalho dos funcionários públicos com conhecimentos linguísticos na língua de Camões e, por outro, excluir candidatos oriundos da China Interior ou da Região Administrativa Especial de Hong Kong (daqui por diante referida como RAEHK), altamente qualificados mas sem os requisitos linguísticos necessários (isto é, conhecimentos em língua portuguesa) para preencher os tão desejados lugares na administração pública macaense (2008, p. 7).

A manutenção do Português como língua oficial da RAEM até 2049 defendida pelo governo português durante o processo de transição governativo do território e a atração por uma carreira no funcionalismo público são responsáveis pelo crescimento exponencial do número de aprendentes de português no território. No Instituto Português do Oriente (IPOR) o número de alunos inscritos passou de 328 no primeiro semestre do ano letivo 2000/01 para 1298 estudantes em 2009/10 (Tribuna de Macau, 21.01.10, p. 3). Estes números parecem contradizer as projeções feitas por Ieong Wan Chong quando sugeriu a adoção da língua inglesa como língua oficial da RAEM (2000, parágrafo 6.5.1) e as previsões de Mark Bray (2004, p. 235) sobre a improbabilidade do Português se conseguir manter como língua da máquina administrativa mas, na realidade, não o são. Pode haver cada vez mais pessoas a aprender a língua portuguesa mas o seu estatuto é meramente de jure servindo apenas para aceder a um posto ou a uma promoção no funcionalismo público. Na realidade, a utilização do Português em Macau restringe-se quase exclusivamente à redação de documentos oficiais para fins de divulgação pública porque assim o obriga o seu estatuto de língua oficial. Manuel Noronha e Ian Chaplin chegam mesmo a afirmar que a língua usada na comunicação intercultural no setor público não é, como seria de esperar, o Português, mas sim o Inglês (2011, p. 415).

As incongruências que parecem existir entre os estudos académicos e a popularidade dos cursos de língua portuguesa estendem-se igualmente à perceção sobre o uso e a importância da língua inglesa na RAEM. O estudo comparativo dos sistemas de ensino de Hong Kong e Macau, realizado por Bray e Ramsey Koo, descreve como paradoxal o fosso existente entre a importância oficial atribuída ao Português e a realidade linguística do território 
e sublinha que, desde o século XIX, as famílias macaenses promovem, por razões meramente economicistas, a aprendizagem do inglês em detrimento da língua oficial do território (2004, p.156). A análise do sistema educativo multilingue adotado na RAEM, realizada por Young Ming Yee 10 anos depois da transição administrativa, revelou que o uso do Português se restringe ao círculo governativo e contactos de alto nível com a Comunidade de Países de Língua Oficial Portuguesa (2009, p. 419-422). Mais recentemente, na apresentação preliminar dos dados do estudo sobre a mudança das identidades na aprendizagem de línguas que visa informar a formulação de políticas educativas das minorias étnicas da RAEM, Noronha e Chaplin descrevem como as novas gerações dos "filhos da terra" — supostamente mais qualificados nas duas línguas oficiais do território devido às suas raízes sofreram um processo de "desnacionalização" em relação às suas origens, tendo muitos deles abdicado da sua nacionalidade portuguesa e optado por estudar outras línguas que não o Português. Segundo estes dois investigadores da Universidade de Macau, a língua portuguesa também deixou de ser usada no seio familiar dos macaenses, tendo sido substituída por um bilinguismo anglo-chinês (cantonense). A previsão dos autores é de abandono do Português em prol do Chinês (Cantonense) e Inglês (2011, p. 418-22). Apesar da percepção generalizada de que o uso da língua inglesa é cada vez mais prevalente em Macau, durante o último Censo realizado em agosto de 2011, apenas $21.1 \%$ da população de Macau declarou falar Inglês como língua segunda (Macau Daily Times, 17.04.2012).

A grande maioria dos habitantes da RAEM fala pelo menos duas línguas e frequentemente três, ou até mesmo quatro. Um transeunte mais atento às sonoridades linguísticas dos residentes deste minúsculo pedaço de terra irá deparar-se com variadíssimas línguas: Cantonense (isto é, a língua ou, se optarmos pela nomenclatura oficial do governo central chinês, o "dialeto" da província de Cantão), Putonhgua - a língua falada pela grande maioria da população chinesa que tem por base os dialetos falados na região de Pequim e seus arredores), Inglês, Filipino (sobretudo Tagalog), e Português - línguas essas que contribuem para o processo de construção identitária de cada um dos indivíduos que compõem os diferentes grupos sociais que partilham os cerca de $30 \mathrm{~km}^{2}$ que delimitam o espaço físico descrito como RAEM. Note-se, no entanto, que não existe uma língua franca partilhada por todas estas comunidades. Diferentes grupos sociais recorrem a diferentes combinações linguísticas para comunicar com os membros de outros grupos sociais. Os chineses, dependendo de onde são oriundos, falam os dialetos das suas províncias, bem como Cantonense e/ou Putonghua; os Filipinos falam as suas línguas maternas, Tagalog, Inglês e, dependendo da sua entidade patronal, Cantonense ou Português; os Macaenses ou "filhos da terra" falam Cantonense e Putonghua, Inglês e/ou Português. Esta "desarticulação" 
linguística reflete uma comunidade que se constrói com base em grupos que raramente se misturam entre si.

A RAEM apresenta assim uma situação linguística caricata: $83.3 \%$ da população fala Cantonense, os restantes residentes falam diferentes línguas de acordo com a sua origem e, à falta de uma língua franca, $21.1 \%$ da população recorre ao Inglês. Ao contrário do que aconteceu na RAEHK, onde a reforma do sistema educativo implementada pela administração inglesa nas décadas de setenta e oitenta do século XX contribuiu significativamente para a divulgação e consolidação do Inglês (BOLTON, 2008, p. 164), a administração portuguesa nunca interveio ou sequer investiu na educação da população residente em Macau. Lau Sin Peng declara que, entre 1900 e 1980, nada, ou quase nada, foi feito pelo sistema educativo (2009, p. 41). Mesmo a legislação básica, como a Lei de Bases do Sistema Educativo de Macau (Lei no . 11/91/M de 29 de agosto) só foi elaborada e aprovada já depois de se terem iniciado as negociações do processo de transição de Macau. No território de Hong Kong o número de escolas em que a língua de instrução é o inglês cresceu gradualmente durante a administração inglesa, segundo Jason Tan (1997, p. 162) porque os encarregados de educação dos alunos acreditam que o inglês é uma mais-valia profissional e a tentativa da administração chinesa de substituir o inglês pela língua materna dos estudantes em várias escolas deparou com forte oposição dos alunos e seus encarregados de educação pelas mesmas razões (CHAN, 2002). Em Macau, pelo contrário, os estudos linguísticos foram "completamente negligenciados", como afirma Gary Ngai em entrevista ao diário de língua inglesa Macau Daily Times (28.06.2010, p. 2). Opinião partilhada por Li Changsen, presidente da Comissão para o Ensino e Investigação de Português do Instituto Politécnico de Macau que, numa entrevista ao jornal Hoje Macau, acusa os portugueses de "não prestarem a devida atenção ao ensino da língua" (05.05.2011, p. 7). Na verdade, a formulação de um plano educativo para o Português proposto pela administração portuguesa esbarrou com tal oposição por parte das escolas e encarregados de educação que nunca chegou a ser implementado. Segundo Lau (2009, p. 29) depois de seis debates entre as entidades educativas e a administração portuguesa que tiveram lugar ao longo de sete anos, foi tomada a seguinte decisão: "Portuguese language teaching is not compulsory and there should be due respect for the autonomy of private schools" que naquela altura, tal como hoje, constituem a grande maioria das escolas da RAEM. Como aconteceu com muitos projetos de preservação histórico-cultural da presença portuguesa em Macau e infraestruturas básicas que foram pensados e implementados durante última década da administração portuguesa, a tentativa de deixar um legado linguístico em Macau decorreu nas vésperas da partida. $\mathrm{O}$ Instituto Português do Oriente foi criado em 1989 com o objetivo de "preservar e valorizar a presença cultural portuguesa na zona do Índico e do 
Pacífico" e "concorrer para o intercâmbio e a cooperação entre Portugal e os países do Oriente". E estabelece-se a Escola Portuguesa de Macau que agregou os estabelecimentos de ensino e secções escolares de língua portuguesa existentes no território que foram sendo encerrados.

A transferência administrativa de Macau realizou-se há mais de uma década. No entanto, ainda não foi formalizada uma política de língua para o território e a atual administração da RAEM parece incapaz de definir um rumo no que toca à reforma do ensino. Mais de 20 anos depois de ter sido publicada a Lei de Bases do Sistema Educativo, continua a não existir uma política educativa na RAEM, nem sequer um plano de implementação de uma reforma que responda às necessidades socioeconómicas do território. Sucedem-se os estudos comissionados a entidades independentes locais e internacionais, que são subsequentemente arquivados sem que sejam tornadas públicas as suas conclusões ou acatadas as suas recomendações. Para agravar esta situação caótica, a administração de Fernando Chui Sai On decidiu, um ano depois de assumir funções em dezembro de 2009 e sem motivos aparentes, reorganizar a liderança das instituições ligadas à Educação. As nomeações ou, melhor dizendo, a redistribuição de papéis burocrático-administrativos, foram comparadas a uma "dança de cadeiras" (Ponto Final, 01.04.2011, edição online).

À medida que a economia macaense se consolida e se ramifica por outras indústrias que não apenas o turismo e o jogo, será necessário promover uma economia baseada no conhecimento que terá de ser necessariamente sustentada por um conjunto de pessoas altamente qualificadas capazes de enfrentar a competitividade imposta pela globalização dos mercados. No momento atual, Macau apresenta falta de mão-de-obra não-qualificada (que tem de importar da China Interior ou de países vizinhos como as Filipinas) e mesmo os seus recursos humanos qualificados nem sempre conseguem competir num mercado mais especializado que requer estudos pós-graduados e/ou conhecimentos linguísticos específicos. À laia de exemplo, refira-se a recorrente falta de tradutores e intérpretes português-chinês qualificados. Apesar dos inúmeros cursos de língua e cultura portuguesas proporcionados pelas muitas instituições de ensino superior do território, os serviços jurídicos (públicos e privados) de Macau continuam a recrutar na China Interior os recém-licenciados da mais prestigiada universidade de línguas estrangeiras: a Universidade de Estudos Estrangeiros de Pequim (BFSU, na sua sigla inglesa). Consciente das dificuldades em ensinar português nos quatro anos que dura uma licenciatura, o então chefe do Departamento de Português da Universidade de Macau, Alan Baxter, reclamou - numa entrevista ao diário Tribuna de Macau - mais espaço para esta língua no sistema educativo de Macau, a começar pelas escolas primárias (12.04.2010). 
No documento intitulado Blueprint for Education Modernization, os autores descrevem da seguinte forma os objetivos do investimento na reforma educativa que está a ter lugar na China Interior (30.07.2010, edição online):

Educational development should focus on providing human resources to meet the needs of economic and social development and the overall improvement in the quality of our population. Fundamentally speaking, a country's development and prosperity hinge on the quality of its population, while education is the key to improving the overall quality of the population.

Dois meses depois de tomar posse no Gabinete de Apoio ao Ensino Superior (GAES), Sou Chio Fai apelou à reforma curricular para melhorar a qualidade do ensino em Macau, reconhecendo que o território está a competir com Hong Kong, Zhuhai e China e que se a qualidade do ensino não melhorar à mesma velocidade dessas regiões será um problema para o sistema educativo (Hoje Macau, 06.05.2011, edição online). Apesar das suas boas intenções, Sou Chio Fai dirige um órgão cujas responsabilidades são meramente consultivas e de apoio ao ensino superior e, consequentemente, a sua capacidade de intervenção é reduzida. Acrescente-se ainda que das dez instituições de ensino superior que, à data, existem em Macau, apenas quatro são públicas. No ensino primário e secundário a situação é semelhante, com o número de escolas privadas a ultrapassar o das instituições de ensino público. Assim sendo, a capacidade de influenciar ou intervir no sistema de ensino é bastante limitada. Tal situação não deveria, no entanto, ilibar a administração chinesa de definir uma política de língua e reformar radicalmente o sistema educativo por forma a proceder à sua implementação judiciosa mas célere, sobretudo tendo em conta que as escolhas linguísticas que se fizerem hoje terão um impacto na definição da identidade pessoal, mas sobretudo regional, dos residentes do território.

Apesar das necessidades do mercado de trabalho da RAEM, das recomendações dos académicos e do Governo central chinês e até do reconhecimento, por parte dos dirigentes políticos do território, da urgência de uma reforma educativa, o governo da região continua a não ter uma missão concreta ou sequer objetivos claros no que toca à reforma do sistema educativo e ao papel da língua portuguesa no território. Contrariado a atual tendência regional para o bilinguismo ou até mesmo plurilinguismo como formas de construção identitária e instrumentos de reforma e desenvolvimento socioeconómico, o sistema educativo da RAEM continua a promover o monolinguismo a quase todos os níveis escolares. Existem várias escolas secundárias com "secções" inglesas, chinesas e até portuguesas e cursos superiores cuja língua de instrução é o português ou o inglês, mas não existe uma verdadeira política de bilinguismo ou sequer tentativa para o implementar.

16 fragmentum, N. 35, parte II. Laboratório Corpus: UFSM, Out./ Dez. 2012 
O Plano para o Desenvolvimento da Educação Primária e Secundária para os anos de 2011 a 2020, publicado em janeiro de 2011, não define nenhuma estratégia reformista nem oferece soluções para a persistente falta de recursos humanos qualificados, e também não promove nenhuma política de bilinguismo, optando por — no parágrafo 2.2.1 — fazer apenas referência à necessidade de promover a língua chinesa (não Cantonense mas Putonghua) a par de uma língua estrangeira (sem mencionar qual).

Li Wei, um dos maiores peritos mundiais na área do bilinguismo e educação bilingue, reconhece a dificuldade em escolher uma língua de instrução em países ou regiões multilingues, mas argumenta que este tipo de educação pode ser benéfico não apenas para o indivíduo mas também para a sociedade. Li faz notar que não existem dados científicos que provem as vantagens de sistemas educacionais monolingues sobre o bilinguismo e conclui: "For a linguistically diverse country, maintaining the ethnic-group languages alongside the national or official language(s) can prove to be an effective way to motivate individuals while unifying the nation" $(2007$, p. 12). $\mathrm{Li}$ defende que o bilinguismo ou até o trilinguismo funcionam como uma mais-valia econômica em relação ao monolinguismo. À medida que a globalização avança e as economias nacionais se tornam cada vez mais interdependentes, um falante com duas ou mais línguas terá sempre mais oportunidades e, tal como afirma Rebecca Freeman, apresentará sempre maiores benefícios cognitivos, sociais, pessoais e económicos (2007, p. 9). Já em 2003, Jim Cummins afirmava que o "contacto intercultural é um dos mais elevados de todos os tempos e exige qualificações multiculturais e plurilinguísticas não apenas dos indivíduos mas também das nações". De facto, nações mais pequenas e monolingues como os Países Baixos e a Dinamarca têm vindo a promover desde os anos quarenta currículos educacionais bilingues que beneficiam significativamente o desenvolvimento social e a promoção académico-profissional das suas populações e consequentemente da nação. Na Ásia, países como Myanmar, Tailândia, Vietname e Indonésia optaram pelo pluralismo linguistico-cultural (ref. BENSON, 2005, p. 4).

O Governo central chinês apela repetidamente à construção de Macau como um espaço de promoção político-económica entre a China e a Comunidade de Países de Língua Oficial Portuguesa (CPLP). E, numa interessante análise retrospetiva dos primeiros 10 anos de administração chinesa do território, Thomas Chung e Henrik Tieben chamam igualmente a atenção para a vantagem competitiva que representa a relação especial que Macau tem com a CPLP. Os autores observam que, num futuro próximo, a concorrência criada pela abertura de casinos em Singapura bem como outras cidades asiáticas irá obrigar a RAEM a ampliar a sua economia para além dos setores do turismo e jogo e sugerem que a relação especial que Macau tem como a CPLP pode funcionar como uma mais-valia (2009, p. 8-13). No setor 
do turismo, Macau há muito que vende a sua "Lusitanidade" promovendo a sua herança arquitetónica de cunho português e cultivando a sua multiculturalidade. Mas tal como o ex-libris de Macau é apenas uma fachada magnificamente decorada, o processo de construção identitária de Macau apresenta-se como uma máscara que esconde um enorme vazio. A herança portuguesa tangível e intangível de Macau está a ser preservada para inglês ver, isto é, para vender como produto turístico que caracteriza a RAEM e a distingue de outros destinos turísticos. No entanto, a relação dos residentes deste espaço com essa herança histórico-cultural há muito que se perdeu. Um inquérito informal de rua realizado pela jornalista Raquel Carvalho para o diário em língua portuguesa, Tribuna de Macau, revela que "Portugal não é apenas uma geografia distante, é uma palavra esquisita aos ouvidos de muitos jovens residentes em Macau." Segundo a jornalista, os jovens entrevistados reconhecem "os pastéis de nata e mais um ou dois pratos da comida portuguesa" e afirmam que "Macau é diferente da China Interior, mas não sabem explicar porquê" (10.06.2010, p. 3). Esta reportagem parece indiciar que, nem mesmo quando confrontados com a sua própria herança históricocultural, os jovens da RAEM reconhecem ou identificam-se com uma identidade coletiva global associada à cultura e língua portuguesas.

Desde que foi dada autorização aos portugueses para se estabelecerem neste pequeno pedaço de terra que Macau funciona como ponto de passagem, mas também de residência de uma enorme variedade de pessoas das mais diversas origens. Ao contrário de Hong Kong, onde o processo de construção identitária se iniciou durante a administração inglesa e esteve sempre associado à formação linguística dos seus residentes, na RAEM sempre se promoveu, como em muitos outros locais por onde passaram portugueses, a coabitação e a miscigenação. Em Macau, essa forma de integração dos portugueses deu inclusivamente origem a um grupo populacional com características muito especificas designado como "os filhos da terra". Não existe consenso entre os investigadores sobre as raízes genéticas e, consequentemente, identitárias desta comunidade (ref. NORONHA e CHAPLIN, 2011, p. 417), mas a designação que escolheram para se destrinçar dos restantes habitantes do território - " "filhos da terra" - sugere um tipo de construção identitária que não tem por base as suas origens genético-culturais mas a terra onde nasceram. O contacto mais estreito entre as comunidades portuguesa e chinesa e a miscigenação dela resultante deu origem ao patuá um crioulo de base portuguesa que durante anos funcionou como língua de comunicação familiar, usado sobretudo entre as mulheres das famílias macaenses. À medida que se generalizava o acesso à escolarização, a lingu maquista passou a estar reservada à interação social informal entre membros da mesma família ou amigos próximos e, com o incentivo das autoridades escolares que baniam o seu uso castigando quem o falasse, foi-se perdendo e 
dando lugar ao português (NORONHA e CHAPLIN, 2011, p. 418). Existem esforços para preservar a língua dos "filhos da terra", mas o número reduzido de falantes fluentes e sua idade avançada irão certamente dificultar a sobrevivência deste crioulo.

Segundo os dados do Censo de 2011 a comunidade portuguesa residente em Macau representa $0.6 \%$ do total populacional mas, tal como os "filhos da terra", este grupo populacional também tem uma relação de afinidade especial com a terra mais até do que um verdadeiro espírito de coesão associado às suas origens ou nacionalidade. É curioso observar o regresso de um conjunto de pessoas que, tendo nascido e/ou crescido em Macau durante a administração portuguesa, saíram do território para estudar ou acompanhando os seus familiares quando estes decidiram ou foram obrigados a retornar a Portugal antes da transferência administrativa do território para a China.

$\mathrm{Na}$ RAEM coabitam ainda três grupos comunitários com características específicas e muito diferentes entre si: i) os chineses de Macau, ou, melhor dizendo, as famílias chinesas habitantes no território há várias gerações; ii) os chineses oriundos de diversas províncias vizinhas, incluindo a RAEHK, residentes em Macau, isto é, os trabalhadores migrantes chineses mais recentes mas alguns deles com filhos já nascidos em Macau; e iii) um grupo de estrangeiros que agora inclui nacionalidades tão diversas como birmaneses, indonésios, filipinos, americanos e australianos. A transferência de poderes e o desenvolvimento económico da RAEM contribuíram para o crescimento populacional. Dados do Censo de 2011 revelam que 59.1\% da população residente não nasceu em Macau e que 46.2\% dos residentes de Macau são oriundos da China Interior (Macau Daily Times, 17.04.12, edição online).

Estas comunidades partilham o mesmo espaço físico mas frequentam círculos socioeconómicos distintos e apenas em algumas situações profissionais se misturam ou relacionam. Os indivíduos cultivam um sentimento de pertença ao seu grupo social, diferenciando-se assim de outros grupos. Um exemplo interessante é a distinção que os indivíduos de nacionalidade chinesa fazem entre os imigrantes chegados há menos de uma geração e as famílias que residem no território há várias gerações. Mesmo entre a comunidade portuguesa existe uma clara diferenciação entre aqueles que "ficaram", isto é o pequeno grupo de portugueses que no momento da transferência decidiu permanecer no território em vez de regressar a Portugal e aqueles que chegaram ou, em alguns casos, regressam depois de 1999. Cada grupo social fecha-se sobre si próprio e cultiva diferentes formas de "estar" em Macau. Os filipinos, bem como a crescente comunidade de estrangeiros de outras nacionalidades que trabalham sobretudo na indústria do jogo, sentem que estão "de passagem" pelo território. Entre a comunidade de trabalhadores 
filipinos é frequente os pais separarem-se das gerações mais novas para que estas sejam escolarizadas nas Filipinas, por forma a facilitar um possível regresso familiar ao país. A transição administrativa e o desenvolvimento da indústria do jogo não apenas reforçaram a natureza multicultural da RAEM como aceleraram o processo de integração (sócio-profissional, mas não linguístico) dos recém-chegados. Não surpreende, portanto, a inexistência de um sentimento de "pertença" à terra que se traduza numa identidade coletiva ou coesão comunitária.

Segundo Andrew Simpson (2007), a construção da identidade de Hong Kong decorreu nas décadas de sessenta e setenta do século XX quando a comunidade residente naquele território assimilou as influências ocidentais e construiu uma "nova mistura cultural híbrida sino-ocidental" que tornou a sociedade de Hong Kong mais "cosmopolita e global" do que os seus vizinhos. Simpson acrescenta que, apesar de nem todos os residentes de Hong Kong terem aderido a esta nova identidade, existe entre os jovens nascidos naquela região administrativa especial com estudos superiores e salários elevados a perceção de ser Hongkonguese (2007, p. 173-5). Em Macau, tal processo e construção identitário ainda está por acontecer. Sobretudo porque, ao contrário de outros países e regiões da mesma área geográfica e de características histórico-culturais semelhantes a Macau, nunca houve, por parte das autoridades portuguesas e chinesas, nenhum investimento naquele que é um dos principais instrumentos desse processo de construção: a língua.

É incontestável que o processo de construção identitária está associado à língua ou línguas partilhadas por uma determinada comunidade. Nas palavras de Shahrzad Mahootian (2007, p. 84):

[...] identity is built, maintained and altered through social relationships and since language is the main tool of communication through which social relationships are built, and all such relationships serve to establish one's identity, language can therefore be said to be a constructor of one's identity.

Nas regiões e países vizinhos da RAEM, muitos deles com passados coloniais e processos de independência e construção identitária com alguns traços comuns, os governos recorreram a políticas linguísticas para reforçar, quer a sua identidade, quer o seu desenvolvimento económico-social. Em Singapura, desde o final da década de setenta que o governo promove uma política pluricultural e multilingue que alguns investigadores associam ao sucesso económico daquela cidade-estado (OCDE, 2010). Desde a sua génese que os seus líderes compreenderam a importância da língua inglesa, não apenas como um valor socioeconómico acrescentado, mas como forma de reforçar a identidade nacional do país. Bray descreve esta opção política da seguinte forma (2004, p. 219):

20 fragmentum, N. 35, parte II. Laboratório Corpus: UFSM, Out./ Dez. 2012 
Singapore is an example of a postcolonial setting where policy makers decided to retain an ongoing major role for the colonial languages because it was a force for unification and for differentiation from neighbouring states. In this city-nation, English was used to bring together different racial and language groups and to distinguish Singapore from Malaysia and other countries.

Tal como muitos outros países do sudeste asiático, a população de Singapura é constituída por diferentes comunidades migrantes de várias etnias e com raízes culturais e religiosas diversas. A partir da sua independência, esta cidade-estado decidiu construir uma nação bilingue recorrendo ao Inglês para cimentar a unidade nacional e como instrumento educacional no processo de implementação de uma sociedade do conhecimento. Mas o "grande salto em frente" ocorreu na década de noventa com um conjunto de reformas educacionais em todos os níveis de ensino, desde o pré-escolar ao ensino universitário (GOPINATHAN, 2009, p. 29-30).

Outros estados multiculturais e/ou plurilingues da região, como as Filipinas e a Malásia, seguiram-lhe o exemplo, adotando políticas de promoção do bilinguismo ou até mesmo trilinguismo. Segundo Maya Khemlani David, a Malásia é um país verdadeiramente multicultural e plurilingue onde se falam cerca de 140 línguas. Segundo esta autora, o Malaio foi oficialmente reconhecido como língua nacional em 1957 por forma a promover a coesão nacional nos anos que se seguiram à sua independência, mas o Chinês e o Tamil (línguas maternas de, respetivamente, $32 \%$ e $9 \%$ da população) continuaram as ser usados nas escolas. A partir de 2003, com o objetivo de incentivar o desenvolvimento económico do país, o governo impôs o ensino obrigatório em língua inglesa das disciplinas de matemática e ciências (DAVID, 2008, p. 79). A mesma autora descreve a situação linguística das Filipinas da seguinte maneira: "no arquipélago filipino, um país multiétnico onde são faladas 18 línguas, a política governamental bilingue em vigor desde 1974 e revista em 1987 declara o Inglês e o Filipino (Tagalog) como línguas oficiais nacionais e, consequentemente, estas línguas são usadas como línguas de instrução em todos os níveis de escolaridade” (2008, p. 80-81).

Em Hong Kong, verificou-se um processo de construção identitária sociocultural, mas também linguístico alimentado por um vivo debate público. A construção da identidade regional da RAEHK processou-se através das línguas inglesa e cantonense. Simpson afirma que as duas línguas coexistem cada qual com uma função diferente: "Cantonese fulfilling a low-domain functions and English being used by an expanding elite in high-level functions and increasingly being acquired in schools" (2007, p. 174-5). David Chor Shing Li sublinha igualmente a importância da língua inglesa como língua de instrução nas instituições de estudos superiores (2008, p. 209). De acordo com este autor, os residentes do território partilham a opinião de que o bilinguismo 
Inglês-Chinês (Cantonense/Putonghua) contribui para o desenvolvimento e prosperidade económica sustentável da região (2008, p. 233). As previsões de Tan (1997) em relação ao futuro linguístico da região concretizaram-se e, hoje em dia, Hong Kong apresenta-se como comunidade trilingue onde o Inglês é percecionado como chave para uma mobilidade profissional internacional, o Mandarim (Putonghua) oferece o acesso ao mercado de trabalho chinês e funciona como símbolo de integração do território na nação chinesa e o Cantonense é visto como língua de interação familiar e social.

O sucesso dos processos de construção identitária nacional e desenvolvimento socioeconómico destes países e região asiáticos foram alcançados através de um forte investimento governamental e supervisão de todas as fases do processo de reforma educativa - produção legislativa, implementação da reforma e controlo dos resultados - complementado por outras políticas governamentais para promover a excelência e competitividade regional ou nacional. O governo de Singapura, por exemplo, promove campanhas internacionais para recrutar os recursos humanos mais qualificados mas apoia a qualificação dos jovens singapurenses através da implementação de uma série de políticas e reformas de apoio à educação com o objetivo de melhorar a qualidade dos serviços prestados apostando sempre no bilinguismo e na internacionalização (ref. GOPINATHAN, 2009, p. 25-30). Consequentemente, os jovens singapurenses estão conscientes da necessidade de alargar os seus conhecimentos à escala global por forma a manterem a sua competitividade num mercado que só funcionará em termos globais se for verdadeiramente internacional. Em Macau, o governo fechou o mercado de trabalho tornando quase impossível recrutar candidatos não-residentes ou dificultando o processo através da imposição de determinadas quotas que devem ser preenchidas com trabalhadores locais. Perante este protecionismo dos seus recursos humanos, os jovens residentes em Macau sabem que nem sequer precisam de se esforçar nos seus estudos ou prosseguir estudos superiores pois, melhor ou pior, todos terão acesso a um posto de trabalho. Os concessionários do jogo em Macau aliciam os jovens do ensino secundário, de 18 e 19 anos, com salários elevados (Hoje Macau, 17.05.2010, edição online) e, apesar das condições de trabalho não serem as melhores e as perspetivas profissionais serem mínimas, muitos jovens tomam esta opção. No que toca aos licenciados, dados de 2009/10 revelam que, entre os diplomados da Universidade de Macau, apenas $11 \%$ optaram por prosseguir estudos de pósgraduação e dos $83 \%$ que entraram no mercado de trabalho, mais de $40 \%$ conseguiram emprego ainda antes de terminar o curso com um salário mensal de 34 mil patacas (mais de $€ 3000.00 / \mathrm{R} \$ 8000.00$ ) (Hoje Macau, 06.04.2011, p. 6).

O resultado desta política é uma sociedade composta por jovens pouco diligentes ou ambiciosos que esperam receber do Governo uma série de benefícios e cuja única aspiração é conseguir um trabalho na função pública. 
Quando era Diretor dos Serviços de Educação e Juventude, Sou Chio Fai afirmou, numa entrevista radiofónica transmitida a 17 de janeiro de 2011, que as gerações mais jovens aparentam não ter nem paixão, nem devoção pelo ensino e que a reforma do ensino em Macau não está dependente de dinheiro, mas de empenhamento (Hoje Macau, 18.01.2011, p. 4). Num interessante artigo sobre as opiniões e expectativas dos jovens estudantes universitários, Vanessa Amaro, jornalista e professora universitária, afirma compreender o desejo dos seus alunos em trabalhar na administração pública porque Macau é "a terra das facilidades" na qual "trabalhar 'no' governo é ganhar a lotaria às prestações: poucas dores de cabeça, um horário certinho para cumprir, bom salário a pingar no fim do mês, 22 dias úteis de férias, 14 salários por ano, subsídios para tudo." Quando perguntou aos seus alunos de Licenciatura em Comunicação o que pensavam sobre uma eventual reforma política, as respostas resumiram-se a um "Não sei... Acho que não vou dar nenhuma opinião, porque não sei bem o que isso é." $\mathrm{E}$ quando os questionou sobre o que fariam por Macau se fossem políticos, ofereceram as seguintes sugestões: "Aumentava o valor do cheque de ajuda de comparticipação pecuniária," "Construía casa baratas para os que nasceram em Macau," "Mandava fazer um parque da Hello Kitty" (Hoje Macau, 11.01.2012).

É verdade que os jovens de Macau se sentem "pouco confiantes nas suas capacidades para tomar decisões ou formar uma opinião e nas suas qualificações linguísticas" (Hoje Macau, 03.03. 2010, p. 6) e "desorientados" no que toca à escolha de uma carreira profissional (Hoje Macau, 17.03.2011, edição online). Apelar ao combate contra a "apatia juvenil" como sugere o coordenador do Gabinete de Estudo das Políticas do Governo da RAEM, Lao Pun Lap, (Hoje Macau, 06.04.2011, p. 6) é, no entanto, infrutífero pois os desafios enfrentados pelos jovens do século XXI são consideravelmente maiores que em gerações anteriores. A world wide web e as redes sociais diluíram as identidades pessoais, sociais e regionais/nacionais e expõem os jovens a problemas imprevistos e sem precedentes. Para além das dores de crescimento normais e destes novos desafios que terão de resolver, os jovens de Macau estão a viver uma crise de identidade profunda que impactará o futuro desenvolvimento socioeconómico da região.

O Governo de Macau não pode continuar a esconde-se atrás de estudos sobre o sistema educativo e propostas de leis na forja deste 2004 e tem de assumir a liderança do setor educativo do nível primário ao superior por forma a implementar uma reforma do sistema que vá de encontro às necessidades e aspirações socioeconómicas dos residentes da RAEM. Essa reforma terá de abarcar uma política de língua bilingue ou trilingue. Existem apenas duas escolhas: Cantonense/Putonghua e Inglês ou Cantonense/Putonghua e Português. Nenhuma delas se pode fazer sem um investimento na construção identitária da população residente. Reconhecendo a dificuldade de 
criar uma "comunidade imaginada" entre um aglomerado populacional que não se identifica com a herança histórico-linguístico-cultural portuguesa, mas considerando o avanço considerável das regiões e países vizinhos em relação à RAEM no que toca à construção de uma identidade linguístico-nacional favorecer a língua inglesa, parece mais viável e, a médio-prazo, mais prático e lucrativo, optar pelo Cantonense/Putonghua e Português. Recomenda-se, por isso, a redação e implementação célere de uma política de língua que conduza a um debate público necessário à consciencialização da população sobre a sua identidade coletiva e regional e o processo de construção da mesma, pois apenas quando a grande maioria dos residentes da RAEM, nascidos ou não no território, e independentemente das suas origens genéticas, se sentirem filhos da terra e adotarem como sua a língua portuguesa, poderemos reconhecer (e estudar) a existência de uma identidade regional do território.

\section{Referências}

2011 Census results: Population grew 26.9 percent on the last decade. Macau Daily Times. Macau. 17 abr. 2012. Disponível em: <http://www.macaudailytimes.com.mo/macau/35215-2011-Census-resultsPopulation-grew-269-percent-the-last-decade.html>. Acesso em: 22.jun.2012. Alan Baxter: "Mais espaço para o Português no sistema educacional. Tribuna de Macau. Macau. 12. abr. 2010. p. 2-3.

AMARO, Vanessa. Na Terra das Facilidades. Hoje Macau. 10.jun.2012. p. 19. BENSON, Carol. The importance of mother tongue-based schooling for educational quality - Commissioned Study for Education for All Global Monitoring Report. 2005.2 Disponível em: <unesdoc.unesco.org/images/0014/001466/146632e.pdf>. Acesso em: 2.fev.2011.

BOLTON, Kingsley. The sociolinguistics of Hong Kong and the space for Hong Kong English. (eds). Kingsley Bolton and Han Yang. Language and Society in Hong Kong. Hong Kong. Open University of Hong Kong Press. 2008. p. 157-193.

BRAY, Mark; KOO, Ramsey. Postcolonial patterns and paradoxes: language education in Hong Kong and Macao. Comparative Education, v. 40, n. 2, 2004. p. 215-239.

. Education and Society in Hong Kong and Macao: Comparative Perspectives on Continuity and Change. 1999. Hong Kong. Comparative Research Centre / The University of Hong Kong / Kluwer Academic Publishers. 2004.

CARVALHO, Raquel. Portugal, que forma distante de vida. Tribuna de Macau. Macau. 21.jan.2010. p. 3.

24 fragmentum, N. 35, parte II. Laboratório Corpus: UFSM, Out./ Dez. 2012 
Rui Rocha acredita em boa articulação do IPOR com o ICA.

Tribuna de Macau. Macau. 10.jun.2010. Disponível em: $<$ http://www.jtm.com.mo/view.asp?dT=336703002> Acesso em: 10.jun.2010.

CHAN, Elaine. Beyond Pedagogy: language and identity in post-colonial Hong Kong. British Journal of Sociology of Education, v. 23, n. 2, 2002. p. 271285.

CHAN, Kahon. Geração Exclusão. Hoje Macau. 3.mar.2010. p. 6.

CHUNG, Thomas; TIEBEN, Hendrik. Macau: Ten Years after the Handover. Journal of Current Chinese Affairs, v. 38, n. 1, 2009. p. 7-17.

CUMMINS, Jim. Bilingual Children's Mother Tongue: Why Is It Important for Education?. 2003. Disponível em: <www.fiplv.org/Issues/CumminsENG.pdf>. Acesso em: 4.dez.2010.

DAVID, Maya Khemlani. Language Policies - Impact on Language Maintenance and Teaching Focus on Malaysia, Singapore and The Philippines. (eds.). Tjeerd de Graaf, Nicolas Ostler and Reinier Salverda. Endangered Languages and Language Learning. Proceedings of the Foundation for Endangered Languages XII, 24-27 September 2008 Fryske Akademy and Mercator European Research Centre on Multilingualism and Language Learning.

Dinheiro não traz facilidade: DSEJ diz que falta sinceridade e paixão para melhorar a educação. Hoje Macau. Macau. 18.jan.2011. p. 4.

FREEMAN, Rebecca. Reviewing the Research on Language Education Programs. (eds.). Ofélia García \& Colin Baker. Bilingual Education: An Introductory reader. Clevedon. Multilingual Matters. 2007. p. 3-18.

Gary Ngai: Language Studies have been overlooked. Macau Daily Times. Macau. 28. jun. 2010. p. 2.

GOPINATHAN, Saravanan. Globalization, the State and Education Policy in Singapore. (eds.). Mark Bray and W. O. Lee. Education and Political Transition: Themes and Experiences in East Asia. 2. ed. Hong Kong. Comparative Education Research Centre / University of Hong Kong. 2001. p. 21-36.

IEONG, Wan Chong. Macau 2010: the long term objectives and development strategies in 20 years. Macau. Macau Development Research Centre / Macau Association of Economic Sciences. 2000.

LAU, Sin Peng. A History of Education in Macau. Traduzido por Sylvia S. L. Ieong \& Victoria L. C. Lei. Macau: Faculdade de Educação / Universidade de Macau. 2009.

LEUNG, Virginia. Estudantes desorientados. Hoje Macau. Macau. 17.mar.2011. Disponível em: <http://hojemacau.com.mo/?p=10710> Acesso em: 17.mar.2011.

. Guerra à apatia juvenil. Hoje Macau. Macau. 6.abr.2011. p. 6. 
LI, David C. S. The functions and status of English in Hong Kong: a post1997 update. (eds.). Kingsley Bolton \& Han Yang. Language and Society in Hong Kong. Hong Kong. Open University of Hong Kong Press. 2008. p. 194-240.

LI, Wei. Dimension of bilingualism. Ed. Li Wei The Bilingualism Reader. 2.ed. London. Routledge. 2007. p. 3-22.

MAHOOTIAN, Shahrazad. Contact Media: Language Choice and Identity in the New World. Ed. Nancy Mae Antrim. Seeking identity: Language in Society. Newcastle. Cambridge Scholars Publishers. 2007. p. 81-90.

MOODY, Andrew. Macau English: status, functions and forms. English Today, v. 95, n. 3, 2008. p. 3-15.

NORONHA, Manuel; CHAPLIN, Ian. Researching Changing Language Learnibg Identities for Ethnic Minority Education Policy Formulation: A Case Study of Macau S.A.R., China. Filologia Linguística Portuguesa, v. 13, n. 2, 2011. p. 409-440.

NUNES, Sónia. Educação na dança das cadeiras. Ponto Final. Macau. 1. abr. 2011.

Disponível

em:

$<$ https://pontofinalmacau.wordpress.com/2011/04/01/educacao-na-dancadas-cadeiras/>. Acesso em: 22.jun.2012.

PINHEIRO, Gonçalo Lobo. Canudo e patacas no bolso. Hoje Macau. Macau. 6.abr.2011. p. 6.

. Li Changsen: "Os portugueses não prestaram a devida atenção ao português". Hoje Macau. Macau. 5.mai.2011. p. 6-7.

SIMPSON, Andrew. "Hong Kong." Ed. Andrew Simpson. Language and national identity in Asia. Oxford. Oxford University Press. 2007. p. 168-185. SOU, Chio Fai: "A reforma curricular é fundamental." Hoje Macau. Macau. 6.mai.2011. p. 10-11.

Strong Performers and Successful Reformers in Education: Lessons from PISA for the United States. OCDE. 2010. Disponível em: <www.oecd.org/dataoecd/32/50/46623978.pdf>. Acesso em: 10.jun.2010.

TAN, Jason. "Education and Colonial Transition in Singapore and Hong Kong: comparisons and contracts.” Eds. Mark Bray \& W. O. Lee. Education and Political Transition: Implications of Hong Kong Change of Sovereignty. Hong Kong. Comparative Education Research Centre / University of Hong Kong. 1997. p. 157-166.

YOUNG, Ming Yee Carissa. Multilingual Education in Macau. International Journal of Multilingualism, v.6, n. 4, 2009. p. 412-425.

YUE Xuying, Zhang Zongtang, Wu Jing \& Zhao Chao. A Blueprint for Educational Modernization: The Birth of the Outline of China's National Plan for Medium and Long-term Education Reform and Development. Xinhua.net. 30.jul.2010. Disponível em: <http://www.moe.edu.cn/publicfiles/business/htmlfiles/moe/moe_2862/20

26 fragmentum, N. 35, parte II. Laboratório Corpus: UFSM, Out./ Dez. 2012 
1010/109029.html> Acesso em: 29.jan.2011. 